\title{
OS COMPONENTES DA LÓGICA ARGUMENTATIVA NO GÊNERO REPORTAGEM: UMA PROPOSTA DE ENSINO
}

\author{
Jaqueline Salviano de Sousa ${ }^{1}$ \\ (UNIVERSIDADE FEDERALDO PIAUÍ) \\ João Benvindo de Moura² \\ (UNIVERSIDADE FEDERALDO PIAUÍ)
}

\begin{abstract}
RESUMO
O presente trabalho tem por objetivo analisar os componentes da lógica argumentativa no gênero reportagem, buscando evidenciar a construção de sentidos para uma proposta de ensino. Trata-se de um trabalho bibliográfico de natureza qualitativa e interpretativa, cujo corpus foi composto por três reportagens publicadas nas edições 34, 37 e 38/2018, da revista Revestrés. Os fenômenos foram identificados, classificados e analisados culminando com a redação da pesquisa. $\mathrm{O}$ trabalho tem como base a Teoria Semiolinguística do linguista francês contemporâneo Patrick Charaudeau com ênfase no modo de organização argumentativo do discurso. Como resultados, percebemos que a organização da lógica argumentativa se dá através das relações assertivas e das articulações lógicas das sentenças, visto que a conjunção "e", a disjunção "ou" e a operação de finalidade "para", foram os modos de encadeamentos mais recorrentes nas reportagens, responsáveis pelas relações de causalidade na argumentação. O escopo do valor de verdade foi estabelecido através da generalização. Concluímos que o gênero reportagem constitui-se num rico material para estudo em sala de aula, possibilitando, além do estudo das tipologias descritiva e narrativa, também a abordagem da argumentação.
\end{abstract}

PALAVRAS-CHAVE: Discurso. Argumentação. Revista Revestrés. Ensino.

\begin{abstract}
This paper aims to analyze the components of argumentative logic in the reporting genre, seeking to highlight the construction of meanings for a teaching proposal. This is a bibliographical work of qualitative and interpretative nature, whose corpus was composed by three reports published in the editions 34,37 and 38/2018, of Revestrés magazine. The phenomena were identified, classified and analyzed culminating with the writing of the research. The work is based on the Semiolinguistic Theory of contemporary French linguist Patrick Charaudeau with an emphasis on the mode of argumentative organization of discourse. As a result, we realize that the organization of argumentative logic occurs through assertive relations and logical articulations of sentences, since the conjunction "and", the disjunction "or" and the operation of purpose "to", were the modes of chains. recurrent in the reports, responsible for the causal relations in the argument. The scope of the truth value has been established through generalization. We conclude that the reportage genre is a rich material for classroom study, allowing, in addition to the study of descriptive and narrative typologies, also the approach of argumentation.
\end{abstract}

KEYWORDS: Speech. Argumentation. Revestrés Magazine. Teaching.

\footnotetext{
1 Jaqueline Salviano de Sousa é graduanda em Letras-Português pela UFPI, bolsista PIBIC e membro do Núcleo de Estudos e Pesquisas em Análise do Discurso - NEPAD/UFPI. E-mail: jaquelinesalviano2016@gmail.com

${ }^{2}$ Possui Pós-doutorado em Linguística pela UFMG. Professor da Graduação e Pós-graduação em Letras da UFPI. Editor da revista Form@are (PARFOR/UFPI). Fundador e atual coordenador do Núcleo de Estudos e Pesquisas em Análise do Discurso - NEPAD/UFPI. E-mail: ibenvindo@ufpi.edu.br.
} 


\section{INTRODUÇÃO}

É cabível ressaltar que a noção de discurso envolve questões históricas, sociais, políticas, religiosas, culturais e ideológicas, ou seja, o discurso abrange todo o contexto no qual está inserido o sujeito, influenciando no seu dizer. Nesta perspectiva, as publicações que fazem parte da mídia alternativa se caracterizam pela abordagem de temáticas, fatos e opiniões que dificilmente seriam contemplados nos grandes veículos comerciais. Dar voz a determinadas produções culturais, aspectos sociais, estabelecimentos, personagens desconhecidos é objetivo maior de uma grande quantidade de publicações que circulam em nosso meio. A revista Revestrés é uma delas. Tal postura, no entanto, não as exime de expressão de um caráter ideológico, uma vez que o mesmo é inerente à própria linguagem humana.

A presente pesquisa objetiva identificar os componentes da lógica argumentativa, evidenciando a construção dos mesmos no gênero reportagem, nos discursos da revista Revestrés, informativo da mídia cultural editado em Teresina-PI. Partindo desse pressuposto, a análise se desdobrará sob o modo de organização argumentativo do discurso, em que será analisada a seção reportagem da revista supracitada.

Trata-se de um trabalho interpretativo, cujo corpus foi composto por três reportagens de 2018, referentes às edições 34, 37 e 38, da revista supracitada. A escolha da seção reportagem justifica-se por ser o gênero mais recorrente na publicação apresentando uma forte característica argumentativa. Como suporte teórico para a análise, embasamo-nos, principalmente, na Teoria Semiolinguística de Charaudeau (2016). Com relação aos aspectos metodológicos, trata-se de uma pesquisa qualitativa e interpretativa.

\section{A TEORIA SEMIOLINGUÍSTICA}

Os estudos que se abrigam hoje sob o rótulo de "Análise do Discurso" apresentam-se de variadas formas, a exemplo da Análise de Discurso Crítica proposta pelo teórico inglês Norman Fairclough, a Análise do Discurso Francesa fundada pelo filósofo Michel Pêcheux e o linguista Jean Dubois, e a Teoria Semiolinguística criada pelo linguista francês contemporâneo Patrick Charaudeau, dentre outras. É essa última 
vertente que nos interessa neste trabalho, tendo em vista que a mesma tem sido aplicada com bastante recorrência para estudo dos discursos midiáticos.

A Semiolinguística é uma proposta teórica elaborada pelo linguista francês Patrick Charaudeau, em sua tese de doutorado, e publicada em 1983 na obra Langage et Discours. Trata-se de uma ramificação da Análise do Discurso Francesa, tendo como diferencial a consideração das intencionalidades e da natureza psicossocial da linguagem.

Os estudos sobre a Teoria Semiolinguística, doravante TS, ganharam corpo no Brasil através de pesquisadores da UFMG e da UFRJ. Na UFPI, a teoria tem se destacado como uma das linhas de pesquisa do Núcleo de Estudos e Pesquisas em Análise do Discurso - NEPAD, a partir de publicações tais como Moura (2012) e Moura et al (2015; 2016a; 2016b; 2016c; 2017 e 2018).

A Semiolinguística considera o ato de linguagem como produto de um contexto do qual participam um emissor e um receptor que, por serem pessoas diferentes, podem atribuir a uma expressão linguística diferentes interpretações, dando a elas sentidos não previstos (CORRÊA-ROSADO, 2014, p. 3).

A Teoria Semiolinguística tem como principais postulados o ato de linguagem como encenação, o contrato de comunicação, os imaginários sociodiscursivos e os modos de organização do discurso enunciativo, descritivo, narrativo e argumentativo. É sobre esse último modo de organização que nos deteremos neste trabalho.

\section{O MODO DE ORGANIZAÇÃO ARGUMENTATIVO DO DISCURSO}

Tendo em vista os pressupostos da Teoria Semiolinguística de Charaudeau (2016), busca-se compreender a questão dos modos de organização do discurso, mais especificamente o argumentativo. O modo de organização argumentativo considera os encadeamentos lógicos presentes nos enunciados, em que a argumentação concerne, dessa forma, a uma relação de causalidade. Além disso, apresenta informações implícitas, cuja compreensão o interlocutor precisa ligar às premissas com o seu conhecimento prévio, para concluir a informação ausente por trás do enunciado. Dessa forma, cabe dizer que

A argumentação, portanto, está direcionada à parte do interlocutor que demonstra raciocínio, ou seja, capacidade para refletir e compreender, ainda que seja para chegar ao mesmo resultado. O sujeito que argumenta necessita expressar uma 
convicção e uma explicação de tal maneira que seja capaz de influenciar o interlocutor com força para persuadi-lo a ponto de ser capaz de modificar seu comportamento (MOURA, 2012, p. 44-45).

O modo argumentativo estabelece teses de uma determinada proposta sobre o mundo e, com isso, procura elucidar tal proposta, apresentando, assim, as explicações da mesma. Dessa maneira, no modo de organização argumentativo, o argumento é construído através de proposições que orientam os questionamentos para um valor de verdade.

A partir disso, constituem-se dois tipos de razão, são elas a razão demonstrativa e a razão persuasiva. A razão demonstrativa, segundo Charaudeau (2016), procura estipular nas asserções as relações de causa, por meio dos componentes e procedimentos que constituem a lógica.

Os componentes abarcam as relações assertivas, as articulações lógicas das sentenças, a validação dos enunciados, que contribuem para a construção da argumentação do sujeito falante. Tais componentes visam organizar, nas relações argumentativas, as ideias a partir do uso dos encadeamentos lógicos, para que o raciocínio seja considerado válido. Dessa forma, o uso das asserções nos argumentos consiste em atribuir a questão da autenticidade e da credibilidade ao que está sendo enunciado, assim como os conectores argumentativos que colaboram para o valor explicativo.

Os procedimentos da lógica têm em vista os modos de raciocínio, como as deduções, a explicação, a associação, a escolha alternativa e a concessão restritiva. Cabe destacar que "esses modos de raciocínio se inscrevem numa determinada encenação argumentativa e se combinarão com os componentes dessa encenação" (CHARAUDEAU, 2016, p. 213), ou seja, os procedimentos da lógica, que englobam os modos de raciocínio supracitados, destinam-se de organizar os componentes da lógica, como também sua combinação, com o objetivo de construir um argumento que estabeleça uma validação.

Por outro lado, tem-se a encenação argumentativa, que abrange também os componentes e os procedimentos. Os componentes da encenação argumentativa compreendem o dispositivo argumentativo, os tipos de configuração e as posições do sujeito. O dispositivo argumentativo, em determinada argumentação, caracteriza-se 
pela presença da proposta, da proposição e da persuasão, em que o sujeito que enuncia, com o uso das assertivas, busca colocar suas percepções, a partir da tomada ou não de posição.

Diante da tomada ou não de posição de um jornalista de uma reportagem, por exemplo, Charaudeau (2018) comenta que para a construção de sentido de um determinado discurso, é impossível desvincular o conteúdo da matéria com a opinião particular do autor da reportagem, uma vez que se apresenta nos argumentos uma implicação de tomada de posição, o que se espera a imparcialidade presente nos discursos, porém não é isso que é adotado.

No entanto, os componentes argumentativos consideram também a questão da configuração do argumento, tratando-se de uma troca linguageira através do diálogo ou do texto, isto é, dialogal ou monologal, respectivamente, o que, além disso, contém contratos de fala a fim de fornecer meios para uma possível interpretação, conforme Charaudeau (2016).

Já os procedimentos da encenação argumentativa são de três tipos, os procedimentos semânticos, os discursivos e os de composição. Segundo Charaudeau (2016), os procedimentos semânticos dizem respeito aos valores argumentativos, relativo às questões sociais, enquanto os discursivos referem-se às estratégias linguísticas que produzem efeitos de sentido persuasivos na argumentação.

Os procedimentos de composição concernem às etapas de raciocínio na construção de um texto, seja ele oral ou escrito. Em vista disso, a encenação trata, na situação de comunicação, de construir um sentido considerando o discurso do locutor e a sua intenção e a imagem feita do interlocutor, isto é, as conjunturas sociais e os atores da encenação.

Portanto, cabe dizer que a argumentação, trata de um sujeito argumentante que busca, na comunicação verbal, persuadir o sujeito-alvo através de argumentos de verdade, uma vez que, na interação, ambos conduzem argumentos para que o outro possa aceitar seu ponto de vista, sua opinião acerca de algo sobre o mundo. Com isso, o sujeito que argumenta não deve apenas estabelecer uma ideia sobre um determinado fenômeno do mundo, mas também elaborar argumentos que provem sua autenticidade, a fim de mudar o comportamento e/ou o pensamento do interlocutor. 


\section{A REVISTA REVESTRÉS E SUAS CIRCUNSTÂNCIAS DE DISCURSO}

A revista Revestrés foi fundada em 2011, tendo como responsáveis o jornalista André Gonçalves e o professor Wellington Soares, figuras bastante conhecidas no Piauí pela militância social e cultural que exercem. A Revestrés lida com questões que se relacionam com a Literatura, com a Arte e com a cultura local de Teresina, às vezes, expandindo o seu olhar para o estado do Piauí. Apresenta temáticas voltadas para a valorização dos aspectos culturais e artísticos, propondo um olhar diferenciado, como, por exemplo, enaltecendo ativistas políticos, músicos, escritores e demais artistas locais.

A revista possui uma periodicidade bimestral, resultando na publicação de seis edições por ano. Vale ressaltar, no entanto, que, durante o ano de 2018, período que corresponde ao recorte temporal do nosso corpus, só foram publicadas cinco edições referentes aos meses: janeiro/fevereiro; março/abril; maio/junho; agosto/setembro e novembro/dezembro.

Os leitores podem obter a revista através da assinatura anual da mesma, como também por e-mail ou até mesmo acessar o site da Revestrés, no qual grande parte do seu conteúdo está disponibilizado de forma gratuita. No site, o leitor tem espaço para fazer comentários acerca da revista, enviar sugestões, críticas ou elogios. A publicação também mantém perfis em plataformas digitais como Facebook, Twitter e Instagram, em cujos espaços o público-leitor pode interagir com a mesma, sugerir pautas etc.

\section{A LÓGICA ARGUMENTATIVA}

Na revista Revestrés serão analisadas três reportagens referentes às edições 34, 37 e 38 do ano de 2018. As reportagens apresentam os seguintes títulos, respectivamente: "Me too: como as mulheres são representadas (ou não) no jornalismo?"; "A musa esquecida: Revestrés percorreu a cidade antiga para (re)descobrir suas referências"; "A vida sob atos: na contramão da produção hegemônica, artistas de teatro trilham caminho de luta e reinvenção". A primeira reportagem, da edição 34, tem como responsável a jornalista Samária Andrade, enquanto as outras duas, das edições 37 e 38, são de autoria da Aldenora Cavalcante. 
Com base nesses textos, busca-se analisar a lógica, a partir da Teoria Semiolinguística de Charaudeau (2016).

\section{OS COMPONENTES DA LÓGICA ARGUMENTATIVA}

Conforme mencionamos no capítulo de fundamentação, no que diz respeito à lógica argumentativa, seus componentes são: os elementos de base da relação argumentativa, os modos de encadeamento, as modalidades e o escopo do valor de verdade. Nos deteremos, nesta análise, nos dois primeiros.

\section{a) Os elementos de base da relação argumentativa}

São compostos pela asserção de partida (A1), asserção de chegada (A2) e asserção de passagem, conforme Charaudeau (2016).

No corpus analisado, tais elementos de base podem ser representados em inúmeras estruturas. Recortamos algumas para exemplificar:

\footnotetext{
"Incapaz de manter o jornal aberto. Assim Katherine Graham era vista pelo conselho do jornal The Washington Post - todo masculino" (ANDRADE, 2018, p. 39).
}

Os trechos acima foram retirados da matéria "Me too: como as mulheres são representadas (ou não) no jornalismo?". Ela aborda a problemática da mulher no âmbito profissional, em que se tem uma imagem distorcida da mesma, como incapaz de desempenhar funções que são consideradas aos homens. Podemos observar que A1 corresponde ao sintagma "Incapaz de manter o jornal aberto", enquanto A2 está representado pela expressão "Assim Katherine Graham era vista pelo conselho do jornal The Washington Post - todo masculino". A partir desses dois elementos, podese localizar a asserção de passagem pela inferência de que no período temporal do acontecido, a visão dos homens acerca da atuação da mulher no mercado de trabalho era muito mais regressista e de subordinação. Os homens consideravam-na incompetente o suficiente para ficar encarregada de funções que eram destinadas a eles, por isso, era vista como incapaz na concepção de eles.

O sujeito enunciador da matéria, ao colocar as asserções de partida e chegada, faz com que o leitor ative seu conhecimento de mundo acerca dos estereótipos que cercam a mulher, a respeito da função exercida por ela diante da presença masculina 
no mesmo local de trabalho. Assim, a utilização desse elemento na argumentação, o sujeito enunciador faz uso de um conhecimento partilhado pelo destinatário, da revista Revestrés.

Percebe-se, também, a recorrência das asserções nas demais reportagens. $\mathrm{Na}$ matéria da edição 37, as asserções, já descritas, são apresentadas nos seguintes fragmentos:

"A mudança foi milimetricamente calculada. O presidente da província, José Antônio Saraiva, escolheu uma região entre dois rios, Parnaíba e Poti" (CAVALCANTE, 2018, p. 37).

Com isso, verifica-se a asserção de passagem através do seguinte argumento:

"Ele queria projetar uma nova cidade, desde a sua planta e a disposição dos prédios e monumentos" (CAVALCANTE, 2018, p. 37).

Tais trechos abordam a questão de como foi escolhido o local da capital do Piauí, apresentando A1 como "A mudança foi milimetricamente calculada" e A2 como “O presidente da província, José Antônio Saraiva, escolheu uma região entre dois rios, Parnaíba e Poti”. A partir dessas proposições, pode-se inferir que a asserção de passagem se refere à construção de uma cidade artificial, Teresina, a primeira capital planejada do Brasil. Quanto à edição 38, destacam-se as seguintes asserções de partida e chegada, nesta ordem:

"Profissionais lutam para se reafirmar num contexto em que falta investimento, espaços e há pouco incentivo".

"Mas este não é um cenário recente. A dificuldade sempre fez parte do caminho trilhado pelo artista autônomo" (CAVALCANTE, 2018, p. 32, grifo nosso).

A asserção de passagem é estabelecida por meio de prova:

"Quem se envolve com a produção teatral se desdobra em múltiplas funções, fica à mercê de leis de incentivo e precisa lidar com inúmeras questões, como produzir apresentações que atraiam o público, em uma época em que a bilheteria está diminuindo quando, antes, era a principal fonte de recursos" (CAVALCANTE, 2018, p. 32).

Os fragmentos acima tratam da vida profissional de pessoas que seguem carreira cênica, trabalhando como autônomo, diante disso, o sujeito enunciador preocupa-se, também, em apontar as dificuldades enfrentadas por tais indivíduos que enveredam por essa área. É possível perceber que nas asserções de chegada e partida, colocadas anteriormente, é apresentada uma organização argumentativa diferente das 
asserções exibidas nas matérias das edições 34 e 37 . Isso ocorre porque o sujeito enunciador faz uma ligação entre o antes e o atual acerca da situação de trabalho dos artistas autônomos, em que se percebe, assim, no seguinte enunciado: "Mas este não é um cenário recente", ou seja, refere-se a uma quebra estrutural das asserções já exibidas.

É relevante dizer que o uso recorrente desses três elementos, asserções de partida, de chegada e de passagem, que compõem a argumentação da revista Revestrés, busca atribuir aos fatos ditos um valor de verdade existente entre A1 e A2 para chegar à prova. Essa relação argumentativa constitui uma organização da lógica, a fim de obter a validação. Dessa maneira, a construção da significação, a partir das asserções, é estabelecida quando a ligação entre elas é feita, em que uma decorre da outra permitindo, assim, uma relação de causalidade.

\section{b) Os modos de encadeamento}

Quanto aos modos de encadeamento, podemos verificar uso da conjunção " $e$ " na sequência discursiva abaixo:

"Gracie trabalhava na BBC há 30 anos $\boldsymbol{e}$, enquanto seus colegas homens na mesma função receberam no ano passado cerca de 230 mil libras, a jornalista recebeu 135 mil libras" (ANDRADE, 2018, p. 41, grifo nosso).

A primeira sentença, referente à matéria da edição 34 , trata de uma comparação salarial entre a jornalista Gracie e os seus colegas de trabalho, a fim de provar a desigualdade de gênero no ambiente profissional a partir da diferença do salário de cada um. É possível notar uma relação de causalidade pelo uso da conjunção "e", uma vez que tal conjunção produz na argumentação uma autenticidade nos fatos, de forma a considerar uma informação válida. Já os trechos das matérias 37 e 38, referem-se à dimensão territorial que Teresina ganhou no decorrer do tempo e a informações acerca do evento Festluso. Nota-se o uso da conjunção "e", nos trechos acima, com o objetivo de exercer uma funcionalidade de ligar as orações, como também de estabelecer uma relação argumentativa entre elas, proporcionando uma implicação na argumentação.

Além disso, a disjunção também é presenciada nas respectivas reportagens: 
"Já os homens aparecem mais vezes nas editorias de política, esportes, internacional e polícia - além de vítima, como investigadores ou como perpetradores de violências" (ANDRADE, 2018, p. 42, grifo nosso).

A disjunção utilizada nos argumentos da revista visa conectar expressões, como nos trechos acima retirados das matérias. No primeiro caso, por exemplo, o uso da disjunção "ou" é usado em uma relação de exclusão, isto é, o sujeito enunciador apresenta duas opções de como um indivíduo poderá ser noticiado na revista Revestrés: como investigadores ou como perpetradores de violência, não ambos. Significa dizer que se um determinado indivíduo for apresentado como investigador, implica dizer que ele não é necessariamente um criminoso, ou vice-versa. Essa rela ção exclusiva constrói na argumentação um raciocínio com base na lógica.

Assim acontece nas demais passagens das matérias das edições 37 e 38, em que o sujeito enunciador utiliza a disjunção inclusiva para dizer que a praça pode ser chamada tanto de Landri Sales quanto de Liceu. Essa informação adicional a partir do uso da disjunção leva a considerar a preocupação com o público, uma vez que busca relembrar o nome mais popular e usual de tal praça, com o propósito de aproximar os leitores da revista ao sujeito que enuncia, pois compartilham de um saber, como é possível notar na expressão "como conhecemos". Já a matéria da edição 38, contém também uma disjunção inclusiva, pois o grupo pode receber apoios tanto governamentais quanto privados, isto é, a verdade de receber apoio do governo não exclui a verdade de receber de uma instituição privada.

A presença da restrição e da oposição foi detectada apenas na matéria da edição 37, respectivamente:

"Era preciso que os prédios, monumentos e praças fossem belos. Entretanto, ao longo dos anos, o centro em que se localizava a cidade não comportava mais toda a população" (CAVALCANTE, 2018, p. 37).

No primeiro excerto, nota-se a utilização da restrição para tratar das transformações ocorridas e não esperadas na cidade de Teresina, em que a expectativa era de um resultado belo para o espaço central da capital, mas, devido ao excesso de pessoas habitando o centro da cidade, isso não foi possível. Diante disso, o uso da restrição refere-se a uma causa e consequência, porém, o que resulta não é o esperado dessa relação, ou seja, almejava um ambiente belo, mas pela quantidade de 
pessoas no local isso não foi concretizado. Percebe-se essa restrição pelo uso da marca linguística "entretanto", a fim de encadear tais ideias.

A oposição, na passagem anterior, corresponde à apresentação de duas asserções relativas à contraposição de duas ideias, em que se referem aos comportamentos dos jovens e das crianças. A oposição é estabelecida quando o sujeito enunciador faz um paralelo entre eles perante o ambiente da cidade, opondo as atitudes dos jovens, que frequentavam espaços noturnos para os encontros amorosos, com as atitudes das crianças, que frequentavam os espaços diurnos a fim de diversão e brincadeiras. O feito produzido pela oposição, entre tais grupos de pessoas, na argumentação da revista, objetiva marcar uma aproximação entre o enunciador com os consumidores da mesma, para que estes possam se identificar com hábitos de cada um.

\section{CONCLUSÃO}

Os resultados de nossas análises, com relação à lógica argumentativa, demonstram que os componentes são estabelecidos de acordo com a finalidade. Para tanto, verificamos nas três matérias que o sujeito que enuncia recorre ao argumento de autoridade constantemente para demonstrar a verdade dos fatos, trazendo o depoimento de historiadores, pesquisadores, professores etc. a fim de assegurar as informações como verdadeiras para os leitores da revista.

Percebemos que a organização da lógica argumentativa se dá através das relações assertivas e das articulações lógicas das sentenças, visto que a conjunção "e", a disjunção "ou" e a operação de finalidade "para" foram os modos de encadeamentos mais recorrentes nas reportagens, responsáveis pelas relações de causalidade na argumentação. O escopo do valor de verdade foi estabelecido através da generalização.

Tendo em vista que o trabalho se envereda no modo de organização argumentativo do discurso, pode-se ressaltar a necessidade da realização de pesquisas futuras para os demais modos de organização do discurso, como o enunciativo, o descritivo e o narrativo. Além disso, em uma análise posterior, pode-se também aplicar o modo argumentativo em outro corpus relacionado à revista Revestrés ou outra publicação no mesmo estilo. 


\section{REFERÊNCIAS}

CHARAUDEAU, Patrick. Linguagem e discurso: modos de organização. [coordenação da equipe de tradução Angela M. S. Corrêa \& Ida Lúcia Machado]. - 2. ed., 3a reimpressão - São Paulo: Contexto, 2016.

Langage et Discours. Paris: Hachette, 1983.

Discurso das mídias. tradução de Angela M. S. Corrêa. 2. ed..,4ạ reimpressão. - São Paulo: Contexto, 2018.

CORRÊA-ROSADO, Leonardo Coelho. Teoria Semiolinguística: alguns pressupostos. REVISTA MEMENTO V. 05, N. 2 (julho-dezembro de 2014) Revista Do Mestrado Em Letras Linguagem, Discurso E Cultura Unincor.

MOURA, João Benvindo de. Análise discursiva de editoriais do jornal Meio Norte, do estado do Piauí: a construção de imagens e as emoções suscitáveis através da argumentação. Tese (Doutorado em Estudos Linguísticos). Universidade Federal de Minas Gerais, UFMG, Belo Horizonte - MG, 2012. Disponível em: http://www.bibliotecadigital.ufmg.br/dspace/handle/1843/LETR-974H6D. Acesso em 20 jan. 2019

; BATISTA JÚNIOR, José Ribamar Lopes; LOPES, Maraisa (Org.). Discurso, memória e inclusão social. Recife: Pipa Comunicação, 2015.

; LIMA, Francisco Renato; BORGES, Vanessa Raquel Soares. O jogo de imagens na constituição dos sujeitos discursivos: uma abordagem ideológica e sociopolítica em cartuns. Web-Revista SOCIODIALETO, v. 6, p. 250-268, 2016a. Disponível em: https://docplayer.com.br/19946572-O-jogo-deimagens-na-constituicao-dos-sujeitos-discursivos-uma-abordage m-ideologica-e-sociopolitica-emcartuns.html Acesso em 15.05.2019.

; CARVALHO, André de Moura. O jornal na sala de aula: discursos que constroem e destroem imagens na imprensa piauiense. Revista Form@re, v. 4, p. 3-28, 2016b. Disponível em: http://www.ojs.ufpi.br/index.php/parfor/article/view/5617 Acesso em 15.02.2019.

; MAGALHAES, Jonnia Maria Aguiar; VIEIRA, José Magno de Sousa. Os EU(s) e seus outros: os sujeitos da linguagem estabelecidos na interligação semiolinguística EUc/TUi no filme Bicho de sete cabeças. Percursos Linguísticos, v. 6, p. 37-50, 2016c. Disponível em: http://periodicos.ufes.br/percursos/article/view/13690 Acesso em 15.02.2019.

; BATISTA JÚNIOR, José Ribamar Lopes; LOPES, Marais (Org.). Sentidos em disputa: discursos em funcionamento. Teresina: EDUFPI, 2017. Disponível em: https://drive.google.com/file/d/11V18xIYEwS3LV3UnpkbjQj5xsuXK0zYf/view Acesso em 15.02.2019.

; BATISTA JÚNIOR, José Ribamar Lopes; LOPES, Maraisa (Org.). Linguagem, discurso e produção de sentidos. São Paulo: Pá de palavra, 2018.

ANDRADE, Samária. Me Too: como as mulheres são representadas (ou não) no jornalismo? Revestrés quer saber e faz autocrítica. In: revista Revestrés, p. 38-43, ed. 34, 2018. Disponível em < http://www.revistarevestres.com.br/reportagem/me-too/ >. Acesso em 15.02.2019.

CAVALCANTE, Aldenora. A musa esquecida: Revestrés percorreu a cidade antiga para (re)descobrir suas referências. In: revista Revestrés, p. 36-44, ed. 37, 2018. Disponível em < http://www.revistarevestres.com.br/reportagem/a-musa-esquecida/ >. Acesso em 15.02.2019.

A vida sob atos: na contramão da produção hegemônica, artistas de teatro trilham caminho de luta e reinvenção. In: revista Revestrés, p. 32-39, ed. 38, 2018. Disponível em < http://www.revistarevestres.com.br/reportagem/vida-sob-atos/ >. Acesso em 15.02.2019. 